\title{
A Case Study On Digital Divide And Access To Information Communication Technologies (Icts) In Pulau Tuba, Langkawi, Malaysia
}

\section{Mohamad Yusof Darus', Muhammad Azizi Mohd Ariffin², Muhammad Hafizi Jalil'3, Mohd Azahari Mohd Yusof ${ }^{4}$}

\author{
${ }^{12}$ Faculty of Computer and Mathematical Sciences, UiTM Shah Alam, Selangor, Malaysia \\ ${ }^{3}$ MYREN Network Sdn Bhd, Malaysia \\ ${ }^{4}$ Faculty of Computing and Multimedia, KUPTM, Malaysia
}

Article History: Received: 11 January 2021; Accepted: 27 February 2021; Published online: 5 April 2021

\begin{abstract}
Digital divide is referring to the gap between demographics and regions that have access to modern information and communications technology, and those that don't or have restricted access such as internet. The digital divide continues an important public policy debate that encompasses social, economic and political issues. This research focuses on to identify internet accessibility factors at Pulau Tuba Langkawi. In this research study, we focus on surveying internet accessibility and conducting an interview using quantitative study. Internet accessibility is conducted using OpenSignal application. OpenSignal is application to build a network coverage map of cellular network. For second method, quantitative survey was conducted by interviewing and questionnaire, with the sample size of the survey is 30. From this research, the results show only two spots which has good internet coverage which are near a primary school which are government owned premises. On the other hand, the area along the beach has moderate to bad internet coverage and certain place such as Lubuk Chempedak has very limited internet coverage. From quantitative survey, majority of population has average competent level of knowledge and skills to use the internet application such as email, online banking etc. Furthermore, the results show that majority of population strongly agreed that internet has the potential to increase their income and market their local product to bigger market. However, majority of them unable to use the internet and benefits from it due to poor internet accessibility. Therefore, more IT educational program and training should be given, and the government and local authority must play its part to improve the internet infrastructure so that the population did not continue being left out from the development of digital economy.
\end{abstract}

Keywords: component;Digital Divide; Rural Area; Internet Access; ICTs; E-Commerce

\section{Introduction}

In todays globalized and connected world, digital divide is one of the prevalent issues especially among rural areas communities. According to a study, almost $51 \%$ of global population do not have access to the internet [1], while in Malaysia rural communities only account to $30 \%$ of internet users [2]. This shows a huge disparity in internet penetration among urban and rural population. Due to digital divide, rural communities unable to benefits directly from government initiatives to digitalized economy, education and government services. As for student in rural communities, they will unable to participant in online-based learning especially during mandatory Covid-19 quarantine [3] [4].Thus, it will be difficult for them to lift themselves out of poverty especially small scale farmers even though there are various efforts being done by the government [5].

In Malaysia, among the rural communities which is under-developed and needed attention is in Pulau Tuba, Langkawi. Based on study conducted by [6], the population of Pulau Tuba has high unemployment rate, low education attainment and lack of infrastructure especially in telecommunication. Thus, a comprehensive study needs to be conducted to identify the factors which contributed to digital divide issue among Pulau Tuba population.

Several work has been conducted by [7]-[13] regarding digital divide among rural population. Both, the work of [7], [11] are conducting their digital divide studies in Africa continent. The work of [7] identified digital divide among different genders in Rwanda and their findings shows that digital divide among women is cause by social and cultural factors. While the work of [11] explore the suitable technology to reduce digital divide among African population. But both works did not cover Malaysian population and infrastructure factor. The work of [9] examine the impact of digital divide during Covid-19 pandemic, but the discussion is limited to the impact of digital divide towards the ability of the population in accessing healthcare system. The study of [10], [12] and [13] look at the factor of social privileges and material access to the internet, but it not focusing on broadband infrastructure factors. The work of [8] examine digital divide issue in Northern area of Malaysia which cover the location of Pulau Tuba, but the work did not include infrastructure factor. Based on previous studies, no study 
has been done to identify the factor which cause digital divide among the population of Pulau Tuba even though they have high poverty rate compared to other rural areas in Malaysia.

This paper addresses the gap by performing a study to identify whether internet infrastructure factors contributed to digital divide issues among Pulau Tuba population. The study will involve gathering the cellular internet coverage data on the island and conducting a quantitative survey on the population. The result of the study will benefit the Malaysian government and policy maker to more effectively reduce digital divide issues among the population and ultimately lift them out of poverty.

\section{DIGITAL DIVIDE AMONG PULAU TUBA POPULATION}

Digital divide is a social issue which associated with disparity of information between people who have access to the computer/internet and people who don't. The issue and research on digital divide are not new, it is ongoing for the past 20 years [14] and keep evolving based on economic situation and technological changes. Factors such as culture background, social structure, broadband infrastructure, computer access, and income are one of many factors which contributes to digital divide issue among rural population. Reducing digital divide among rural population should become the priority of the government as it causes income inequality and worsen the poverty among rural population despite increasing GDP of a nation [15]. Thus, to achieve United Nation Sustainable Development Goals (SDG) [16] in eradicating poverty, digital divide problem among rural population especially in Pulau Tuba need to be address accordingly.

Pulau Tuba is an island which is located 3.4 nautical miles from Langkawi Island in Malaysia. The size of Pulau Tuba Island is approximately 20 square kilometers and being inhabited by 4000 people [16]. The economic activities in the island consist of small-scale farming, fishery, traditional craft and other small-scale business/services. Even though it is not located far away from Langkawi Island, which is economically developed, Pulau Tuba is one of area in Malaysia which has high unemployment and poverty rate among its population [6] [17]. Digital divide may contribute to the poverty of the island population as there is lack of proper infrastructure and technology education among the population.

An extensive and reliable broadband infrastructure is one of the enablers of digital economy in rural communities [18] [19]. With internet access, people will able to benefits from government online services [20], doing online business, get an online education and many more online services. But for people without internet access, they will unable to benefits from the online services and will be left out from digital economy. The broadband infrastructure consists of coax cables, fiber optic cables, cellular tower, network or wireless equipment and various other ancillary equipment. To access the internet, the broadband services are delivered via 4G, 3G, DSL, FTTX, WIMAX protocol and the cost of the services is one of the major factors to determine broadband penetration especially among rural population [21] [22].

\section{METHODOLOGY}

There are two methods used in this study. The first method involves surveying internet coverage in Pulau Tuba using an internet coverage maps tools while the second method involve conducting an interview among the local population using quantitative survey.

\section{A. Internet Survey}

For the first method, the survey on internet infrastructure in Pulau Tuba is conducted using OpenSignal application [22]. OpenSignal is a mobile application which use crowdsourcing data to build a network coverage map of cellular network. When smartphone user connects to cellular network in certain area and perform a speedtest, details of the cellular connection data will be collected and stored to OpenSignal server with user consent. OpenSignal will then use the data to map which area has good or bad $3 \mathrm{G} / 4 \mathrm{G}$ cellular coverage. Figure 1 shows OpenSignal Interface overlooking Pulau Tuba, Langkawi. The apps interface shows cellular coverage map based on area; green color indicates the area has a good cellular signal strength while red color indicates the area has a weak cellular signal strength. The interface also able to filter the coverage based on network type (e.g. $3 \mathrm{G}, 4 \mathrm{G})$ and service provider.

The Survey in the first method will be conducted based on flowchart in Figure 2. At the initial stage of the survey, initial information such as Pulau Tuba area size, population size, area of settlement and available telco services. The initial information is obtained from local government office at Pulau Langkawi and journal article from another research. The initial information is crucial as it provide us with better understanding on the local environment and allows us to plan carefully the data collection process on the field. The next stage is going into the field and collect the internet coverage data using smartphone which has been installed with OpenSignal Application. 
In data collection phase of the second method, two smartphones were used, and the cellular signal is gathered at three settlement which are Pekan Tuba, Lubuk Chempedak and TanjungPandan. The cellular coverage data was captured at 10 point in the settlement area and data which collected are signal strength, internet speed and telco tower location. The signal strength $(\mathrm{Dbm})$ of the area shows whether the population able to access telco services in the area. When the population able to access the telco network, to indicate the quality of the services, the Internet speed test was conducted. The last stage is analyzing the data which has been collected and discuss the findings in a written report.

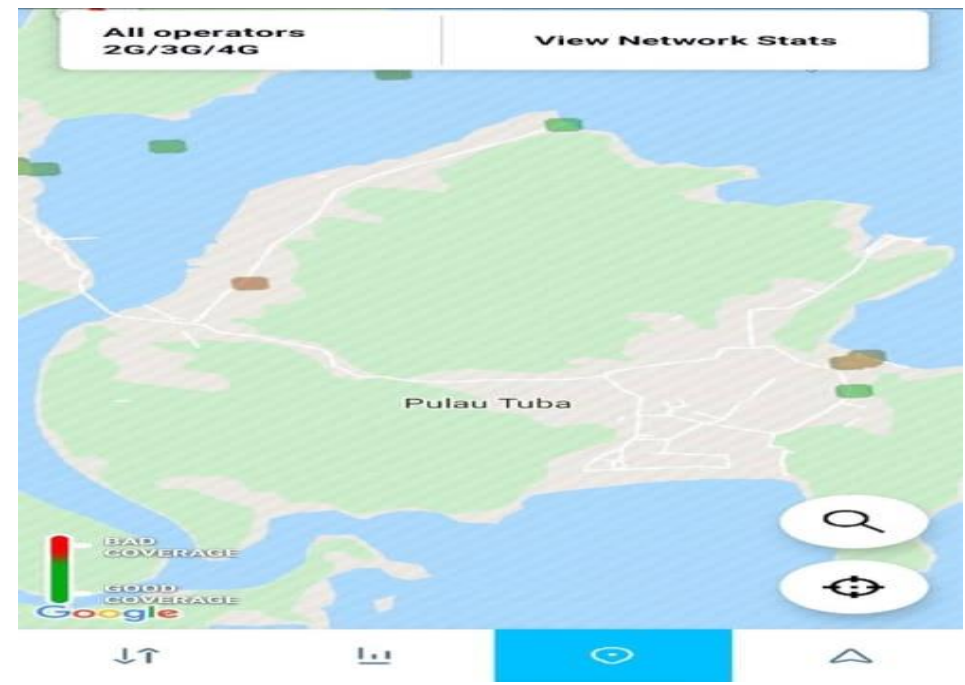

Figure: 1: OpenSignal Mobile Application

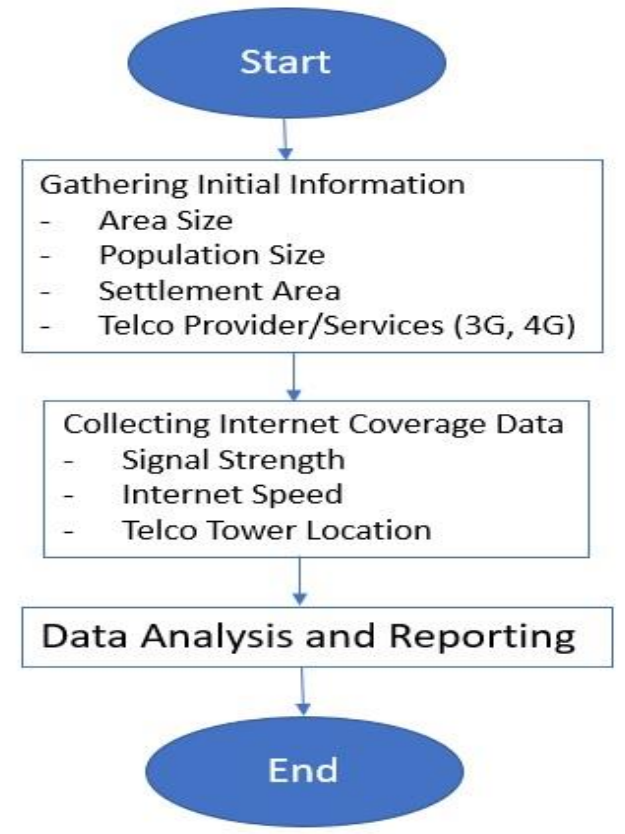

Figure: 2: Internet Survey Method Flowchart

\section{B. Quantitative Survey}

For the second method, quantitative survey was conducted by interviewing the population using a questionnaire. Since Pulau Tuba has small population (4000), the sample size of the survey is 30 and the process took 2 days. The survey process was conducted based on flowchart in Figure 3. Just as the first method, the initial phase involves gathering initial information which was used for planning the data collection phase. The initial phase was also used to obtain permission from local authority and village head to conduct research on their area.

The next phase is about preparing the questionnaire, the question and option is shown in table 1 . The questionnaire was design to gather information regarding population demographic, income, computer and internet access, cost of internet subscription and their sentiment about the usage of internet. After the 
questionnaire has been prepared, the next phase involves going into the field for data collection. The data collection was conducted from door-to-door, around the shop or coffee shop area. As the first method, the data collection was conducted at the Pekan Tuba, Lubuk Chempedak and TanjungPandan settlement. After data has been collected, the questionnaire was compiled, analyzed and reported.

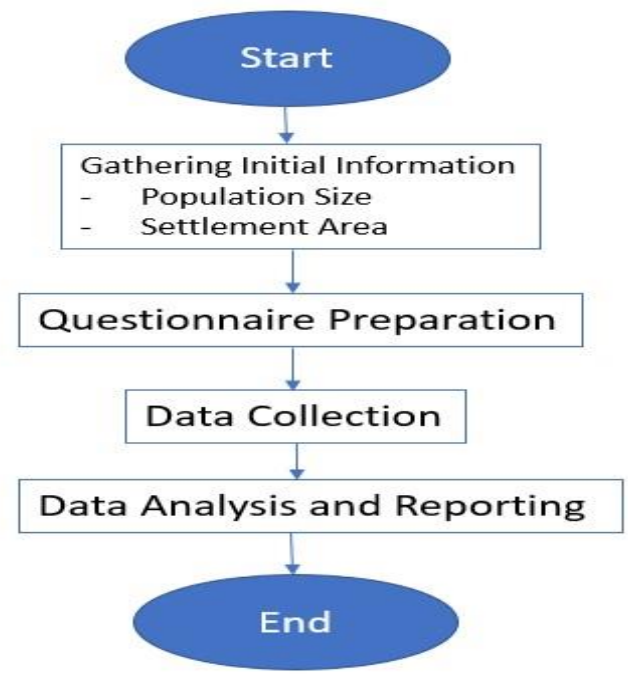

Figure: 3:Quantitative Survey Method Flowchart

Table 1. Questionnaire Sample.

\begin{tabular}{|c|l|l|}
\hline No & \multicolumn{1}{|c|}{ Question } & \multicolumn{1}{c|}{ Respond Option } \\
\hline 1. & Gender & Male or Female \\
\hline 2. & Age & $\begin{array}{l}\text { Less than 20, 20-30, 30-40, 40-50, More than 50 Years } \\
\text { old }\end{array}$ \\
\hline 3. & Occupation & $\begin{array}{l}\text { Fisherman, Farmer, General Worker, Businessman, } \\
\text { Private Company, Other }\end{array}$ \\
\hline 4. & $\begin{array}{l}\text { Occupation } \\
\text { Industry/Field }\end{array}$ & $\begin{array}{l}\text { Agriculture/Fishery, Tourism, Construction, Government, } \\
\text { Services, Other }\end{array}$ \\
\hline 5. & $\begin{array}{l}\text { Monthly } \\
\text { Income }\end{array}$ & $\begin{array}{l}\text { Less than RM1000, RM1000-1500, RM1500-2000, 2000- } \\
\text { 2500, 2500-3000, 3000-5000, 5000-8000, 8000-10000, } \\
\text { More than RM10000 }\end{array}$ \\
\hline 6. & $\begin{array}{l}\text { Smartphone } \\
\text { Ownership }\end{array}$ & Yes or No or Sharing \\
\hline 7. & $\begin{array}{l}\text { Computer } \\
\text { Ownership }\end{array}$ & Yes or No or Sharing \\
\hline 8. & $\begin{array}{l}\text { Internet } \\
\text { Access }\end{array}$ & Yes or No \\
\hline 9. & $\begin{array}{l}\text { Internet } \\
\text { Access } \\
\text { Monthly Cost }\end{array}$ & $\begin{array}{l}\text { Less than RM 50, RM50-100, RM100-150, RM150-200, } \\
\text { More than RM 200 }\end{array}$ \\
\hline 10. & $\begin{array}{l}\text { Internet Usage } \\
\text { Skill }\end{array}$ & $\begin{array}{l}\text { No Knowledge, Not Competent, Average, Able, } \\
\text { Competent }\end{array}$ \\
\hline 11. & $\begin{array}{l}\text { Do you agree } \\
\text { Internet able } \\
\text { to market your } \\
\text { local product? }\end{array}$ & Yes or No \\
\hline 12. & $\begin{array}{l}\text { Do you agree } \\
\text { Internet able } \\
\text { to increase } \\
\text { your monthly } \\
\text { income? }\end{array}$ & Yes or No \\
\hline
\end{tabular}




\section{RESULTS AND DISCUSSION}

The results discussed in the following present the data which are collected using two methodology in Pulau Tuba Langkawi. The data are presented using Pie and Bar chart for visualization to aid analysis process.

\section{A. Internet Survey Result}

The population of Pulau Tuba is concentrated at the area of Pekan Tuba, Lubuk Chempedak and TanjungPandan settlement. Thus, telecommunication infrastructure such as cellular tower was built in the area. In OpenSignal result, area with either $3 \mathrm{G}$ or $4 \mathrm{G}$ coverage was mark with color. Area with red mark indicates bad coverage while green mark indicated a good coverage. Based on $3 \mathrm{G}$ and $4 \mathrm{G}$ specification [23], by average, each mark covers an area of 500 square meters [24]. Area without any color marking indicates either its only covered by GSM/2G or not covered with any cellular network. Either way, both indicated local population unable to access the internet at that area. Figure 4, 5 and 6 shows cellular coverage map of Pekan Tuba, Lubuk Chempedak and TanjungPandan settlement.

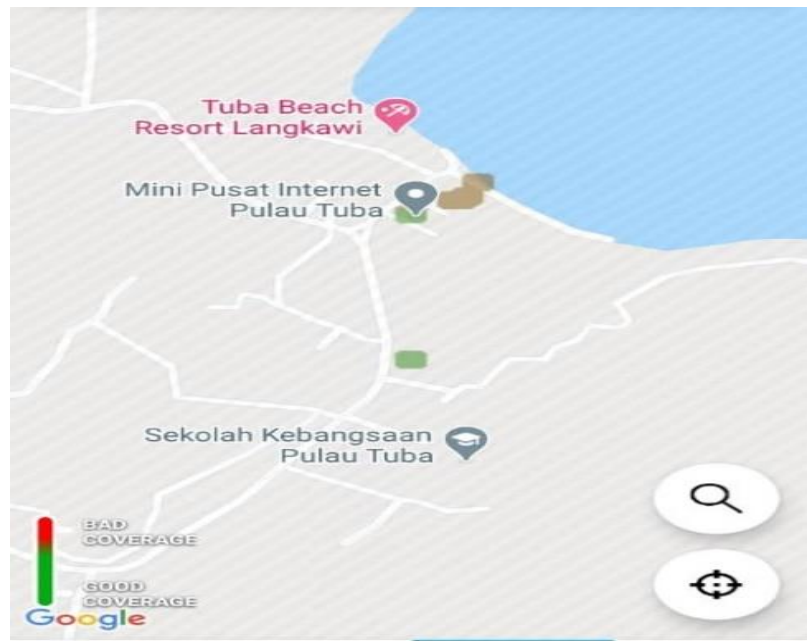

Figure 4: Cellular Coverage in Pekan Tuba

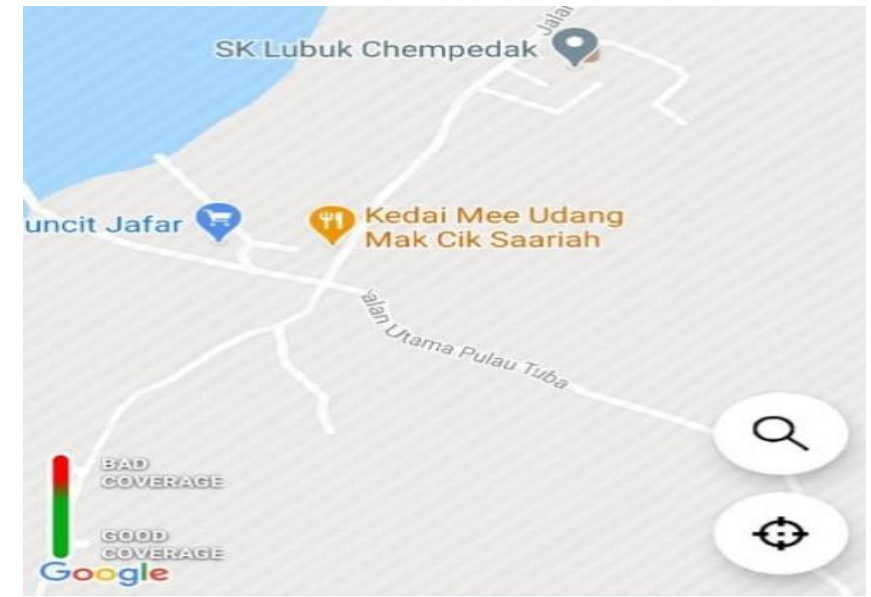

Figure 5: Cellular Coverage in Lubuk Chempedak

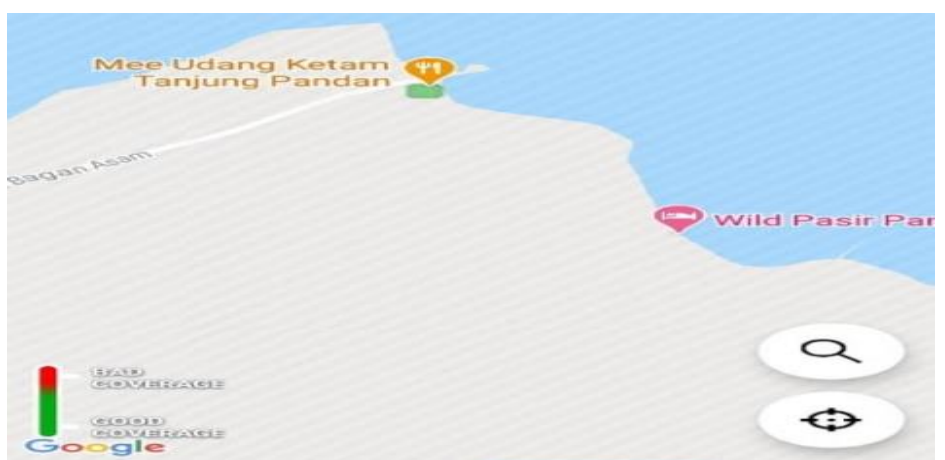

Figure 6: Cellular Coverage in TanjungPandan 
Based on Figure 4, it shows that the area around Pekan Tuba has limited cellular and internet coverage. There are only two spots which has good internet coverage which are near a primary school and mini internet center which are government owned premises. On the other hand, the area along the beach has moderate to bad internet coverage. Based on Figure 5, Lubuk Chempedak has very limited internet coverage as there is only one spot with moderate to bad internet coverage. The area is also located near the area of school premises. For TanjungPandan settlement, data in figure 6 also shows a very limited internet coverage. There is one spot which offer good internet coverage near the jetty area. All cellular network coverage map data was compiled and presented as a pie chart as in figure 7 for better analysis.

\section{Cellular Network Coverage $\left(\mathbf{k m}^{2}\right)$}

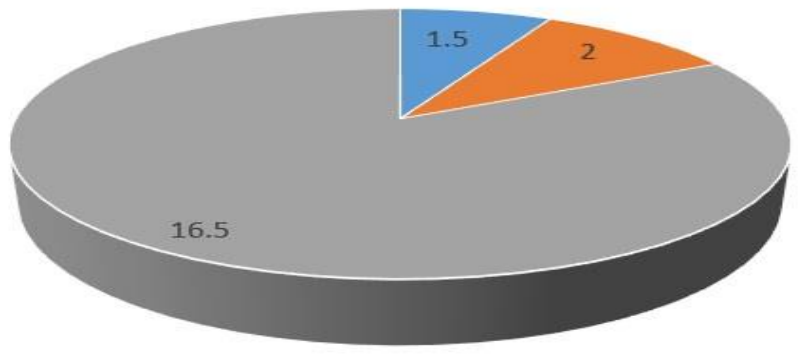

- Good Coverage (3G/4G) = Bad Coverage $(3 G / 4 G)$ | No Coverage

Figure 7: Cellular Coverage Map of Pulau Tuba

Figure 7 shows large portion of Pulau Tuba do not have internet coverage, only 3.5 square kilometers area has internet coverage. The data also shows that the internet coverage is concentrated at the area which has government premises such as school and internet center. This issue will become a factor which contributed to digital divide among the population. With limited internet coverage and infrastructure, only small amount of population will be able to benefits from digital economy. Majority of population will unable to use the computer and internet as a catalyst to lift themselves out of poverty.

\section{B. Quantitative Survey Result}

The result of the quantitative survey on Pulau Tuba population is presented as follows. Figure 8 shows the data regarding devices and internet access. Figure 9 shows monthly cost of subscribing to internet services, Figure 10 the level of knowledge and skills using the internet and lastly Figure 11 shows the population sentiment towards internet usage.

\section{Devices and Internet Access}

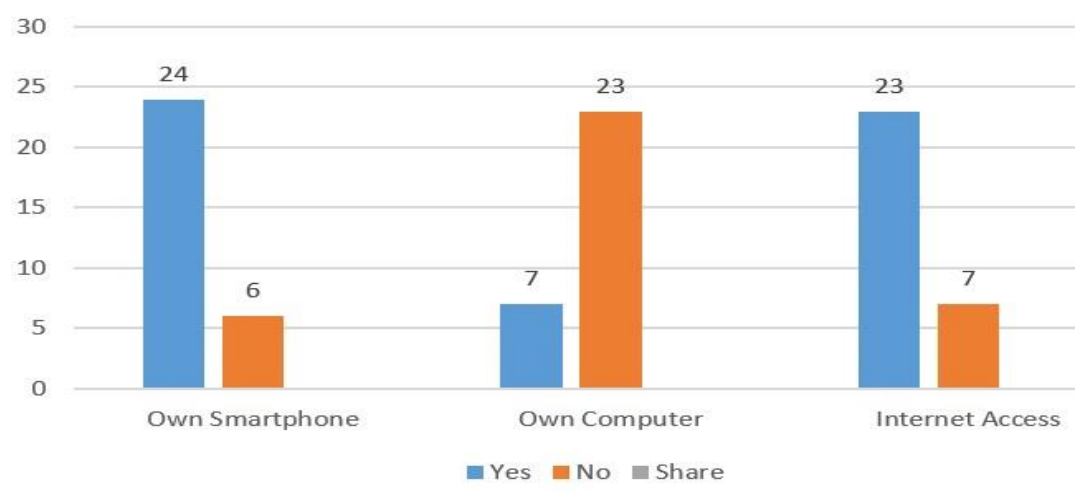

Figure 8: Devices and Internet Access Among Pulau Tuba Population

Figure 8 shows that, majority of the population own a smartphone and minority of the population own a computer. Nevertheless, both smartphone and computer able to connect to the internet. Moreover, figure 8 shows that majority of population able to access the internet. This shows access to computer and technology devices is not a major factor contributed to digital divide among the population. 


\section{Monthly Internet Cost}

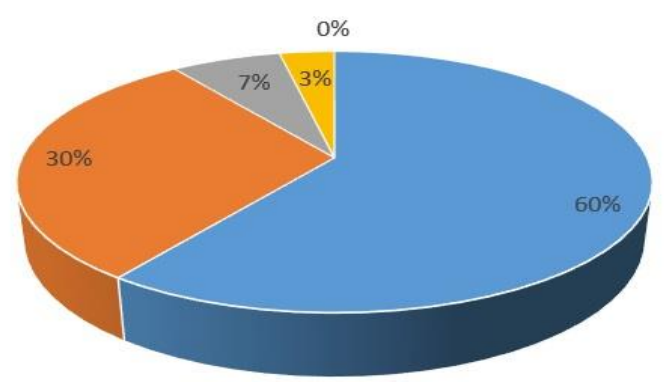

- Less Than RM 50 = RM 50 - 100 = RM $100-150$ = RM 150 - 200 | Rm 200 and Above

Figure 9: Monthly Internet Cost being Spend by Pulau Tuba Population

Figure 9 shows that, $60 \%$ of population spend less than RM 50 monthly for Internet subscription. Based on average monthly income of the population which around RM1000, they able to afford Internet services. The data shows that internet subscription cost is not the main factor that led to digital divide in Pulau Tuba.

\section{Knowledge and Skills Using The Internet}

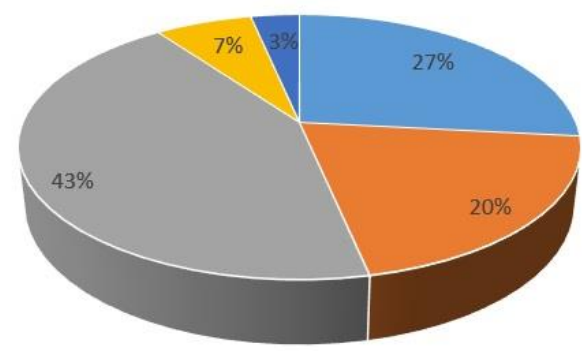

- No Knowledge = Not Competent $=$ Average $=$ Able = Competent

Figure 10: Knowledge and Skills of Using The Internet among Pulau Tuba Population

Based on data in Figure 10, Majority of population has average to competent level of knowledge and skills to use the internet. While, $47 \%$ of population has no knowledge and not competent to use the internet application. The percentage of population with no knowledge should be made lower so that more population are given the opportunity to ripe the benefits of the internet. Thus, more IT educational program and training should be given to the local population.

\section{Population Sentiment Towards Internet Usage}

Do you agree Internet able to increase your monthly income?

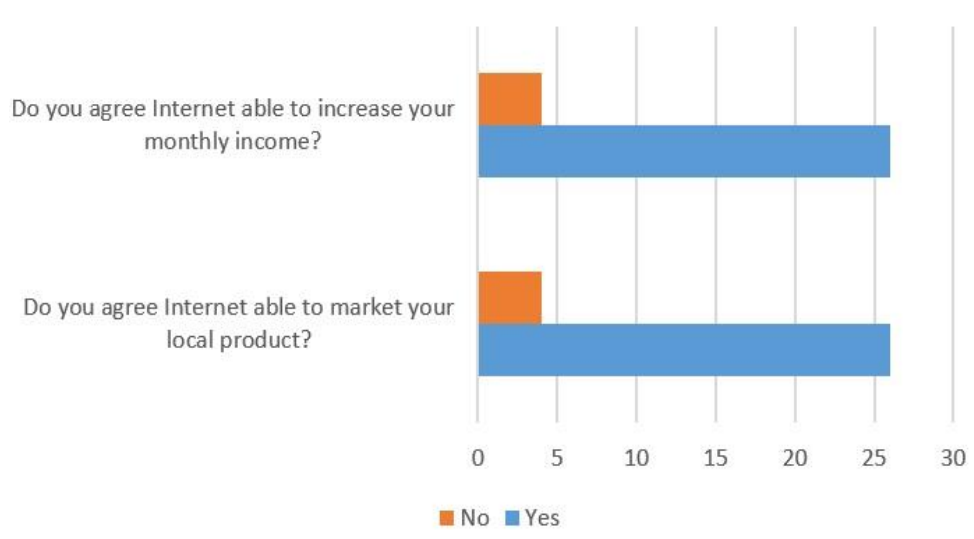

Figure 11: Pulau Tuba Population Sentiment Towards Internet Usage 
Figure 11 shows that majority of population strongly agreed that Internet has the potential to increase their income and market their local product to bigger market. This means the population want to use the internet and understand its potential to improve their living standard and economy condition. But based on Internet survey data, majority of them unable to use the internet and benefits from it due to poor internet infrastructure of the island. This is the main factor which led to digital divide problem among the population of Pulau Tuba. Therefore, the government and local authority must play its part to improve the internet infrastructure so that the population did not continue being left out from the development of digital economy.

\section{CONCLUSION}

The findings from this study shows large portion of Pulau Tuba, Langkawi do not have internet coverage, only 3.5 square kilometers area has internet coverage. This result shows that the internet coverage is concentrated at the area which has government departments such as school etc. Furthermore, the result shows that majority of population strongly agreed that internet connectivity has the potential to increase their income and market their local product to bigger market. For next project, we will develop E-commerce system to commercialize products with a large potential consumer market.

\section{ACKNOWLEDGEMENT}

The authors would like to thank Universiti Teknologi MARA (UiTM) for providing Lestari SDG-Triangle Grant (600-RMC/LESTARI SDG-T 5/3 (142/2019)) to fund this research.

\section{References}

1. R. Pandita, J. \& Kashmir, and I. C. Author, "Internet A Change Agent: An overview of Internet Penetration and Growth across the World," Int. J. Inf. Dissem. Technol., vol. 7, no. 2, pp. 83-91, doi: 10.5958/2249-5576.2017.00001.2.

2. I. U. Survey and I. U. Survey, "Internet Users Survey 2018 | 11 Internet Users Survey 2018," Cyberjaya, 2018. Accessed: Oct. 05, 2020. [Online]. Available: https://www.mcmc.gov.my/skmmgovmy/media/General/pdf/Internet-Users-Survey-2018.pdf.

3. B. M. Mca and M. M. Deemed, "Outcome of Online Teaching-Learning over Traditional Education during Covid-19 Pandemic,” Int. J. Adv. Trends Comput. Sci. Eng., vol. 9, no. 5, pp. 7704-7711, 2020, doi: 10.30534/ijatcse/2020/113952020.

4. A. Endut, P. M. Isa, S. R. A. Aziz, M. N. H. H. Jono, and A. A. Aziz, "e-Learning for Universiti Teknologi MARA Malaysia (UiTM): Campus Wide Implementation and Accomplishments," Procedia Soc. Behav. Sci., vol. 67, pp. 26-35, Dec. 2012, doi: 10.1016/j.sbspro.2012.11.304.

5. M. Khaled Saifullah, F. B. Kari, and A. Othman, "Poverty among the small-scale plantation holders indigenous communities in peninsular Malaysia," Int. J. Soc. Econ., vol. 45, no. 2, pp. 230-245, 2018, doi: 10.1108/IJSE-10-2016-0296.

6. O. -Geoparks, U. Kebangsaan Malaysia, and H. Salleh, "THE GEOPARK AS A POTENTIAL TOOL FOR ALLEVIATING COMMUNITY MARGINALITY SHARINA ABDUL HALIM IBRAHIM KOMOO MUSTAFFA OMAR."

7. N. Mumporeze and M. Prieler, "Gender digital divide in Rwanda: A qualitative analysis of socioeconomic factors," Telemat. Informatics, vol. 34, no. 7, pp. 1285-1293, 2017, doi: 10.1016/j.tele.2017.05.014.

8. S. R. Sheikh Dawood, S. Ghazali, and N. Samat, "Digital divide and poverty eradication in the rural region of the northern Peninsular Malaysia,” Indones. J. Geogr., vol. 51, no. 2, pp. 172-182, 2019, doi: 10.22146/ijg.37758.

9. A. Ramsetty and C. Adams, "Impact of the digital divide in the age of COVID-19," J. Am. Med. Inform. Assoc., vol. 27, no. 7, pp. 1147-1148, Jul. 2020, doi: 10.1093/jamia/ocaa078.

10. A. J. van Deursen and J. A. van Dijk, "The first-level digital divide shifts from inequalities in physical access to inequalities in material access.," New media Soc., vol. 21, no. 2, pp. 354-375, Feb. 2019, doi: 10.1177/1461444818797082.

11. M. P. J. Lavery et al., “Tackling Africa's digital divide 706 639/624/1075/187 comment," Nature Photonics, vol. 12, no. 5. Nature Publishing Group, pp. 249-252, May 01, 2018, doi: 10.1038/s41566018-0162-z.

12. M. L. Fang, S. L. Canham, L. Battersby, J. Sixsmith, M. Wada, and A. Sixsmith, "Exploring Privilege in the Digital Divide: Implications for Theory, Policy, and Practice," Gerontologist, vol. 59, no. 1, pp. E1-E15, Jan. 2019, doi: 10.1093/geront/gny037. 
13. M. Hashim, P. A. Ghani, A. M. Ahmad, A. M. Lokman, and S. M. Sarif, "Towards the development of an e-Village: A case study of Kg. Jenjarom, Kuala Langat, Selangor," Proc. 2nd Int. Conf. Sci. Technol., pp. 1-6, 2008.

14. S. Mihelj, A. Leguina, and J. Downey, "Culture is digital: Cultural participation, diversity and the digital divide," New Media Soc., vol. 21, no. 7, pp. 1465-1485, Jul. 2019, doi: 10.1177/1461444818822816.

15. B. Lester Henry Senior Lecturer, “"Bridging the urban-rural digital divide and mobilizing technology for poverty eradication: challenges and gaps."'

16. D. Griggs et al., "Policy: Sustainable development goals for people and planet," Nature, vol. 495, no. 7441. Nature Publishing Group, pp. 305-307, Mar. 21, 2013, doi: 10.1038/495305a.

17. M. R. A. Razak and dan P. A. Universiti Utara Malaysia. KolejUndang-Undang Kerajaan, Kemiskinankomunitinelayan: satukajiankes di Pulau Tuba, Langkawi. Universiti Utara Malaysia, 2010.

18. N. L. M. Noor and A. Nordin, "Requirements Elicitation for the Technology Conception of a Community Information System for the Indigenous Microenterprise: A Contextual Multi-Analysis Approach on Business and Community Requirements of Batik Making.," Electron. J. Inf. Syst. Eval., vol. 15, no. 1, pp. 102-115, 2012, [Online]. Available: http://search.ebscohost.com/login.aspx ?direct=true\&db=bth\&AN=87403052\&site=ehost-live.

19. M. L. Yap, B. W. Yap, and J. K. Gian Singh, "Investigating the extent of Information Technology (IT) usage in Malaysian Batik industry," Soc. Manag. Res. J., vol. 3, no. 2, p. 125, Dec. 2006, doi: 10.24191/smrj.v3i2.5119.

20. J. Kaur and N. D. Noor Rashid, "Malaysian Electronic Government Adoption Barriers," Public Sect. ICT Manag. Rev., vol. 2, no. 1, pp. 38-43., 2008.

21. K. Salemink, D. Strijker, and G. Bosworth, "Rural development in the digital age: A systematic literature review on unequal ICT availability, adoption, and use in rural areas," J. Rural Stud., vol. 54, pp. 360-371, Aug. 2017, doi: 10.1016/j.jrurstud.2015.09.001.

22. "Mobile Analytics \& Insights | Opensignal," 2020. https://www.opensignal.com/ (accessed Oct. 08, 2020).

23. S. Saravani, C. K. Chakrabarty, N. M. Din, S. M. Norzeli, and M. H. Haron, "Broadband and high efficiency rectifier design based on dual-mode operation for RF ambient energy harvesting," Int. J. Adv. Trends Comput. Sci. Eng., vol. 9, no. 5, pp. 7184-7190, 2020, doi: 10.30534/ijatcse/2020/43952020.

24. Xin Peng, Long Zhang, and Qun Hou, "Study of outdoor signal coverage and network convergence of TD-LTE and TD-SCDMA in high-speed railway," Mar. 2016, pp. 4 .-4 ., doi: 10.1049/cp.2015.0738. 